\title{
Laboratory Evaluation of Asphalt Binder Modified with Crumb Rubber and Basalt Fiber
}

\author{
Li Liu, You Huang ${ }^{D}$, and Zhaohui Liu \\ School of Traffic and Transportation Engineering, Changsha University of Science and Technology, Changsha 400114, China \\ Correspondence should be addressed to You Huang; hyzju@csust.edu.cn
}

Received 21 May 2020; Revised 7 July 2020; Accepted 11 July 2020; Published 5 August 2020

Academic Editor: Yuqing Zhang

Copyright $\odot 2020 \mathrm{Li}$ Liu et al. This is an open access article distributed under the Creative Commons Attribution License, which permits unrestricted use, distribution, and reproduction in any medium, provided the original work is properly cited.

\begin{abstract}
Asphalt pavement subjected to heavy traffic load and harsh environmental conditions can easily build up damage and shorten the service life. In this paper, different dosages of basalt fiber (BF) were introduced into crumb rubber (CR) modified asphalt binder, and a series of laboratory tests were carried out to evaluate the properties and performances. A dynamic shear rheometer (DSR) was employed to evaluate viscosity and rheological properties. Bending beam rheometer (BBR) test and direct tensile test (DTT) were conducted to test the low temperature property. Cone penetration was designed to test shear strength. Results show that the optimum content of $\mathrm{BF}$ is $0.3 \%$ by the weight of asphalt binder based on the overall performance evaluation. Viscosity, complex modulus, fatigue property, rutting resistance, and shear strength are improved by introducing BF into asphalt binder. Stiffness and elasticity are also increased. BBR indicates that ductility at low temperature is reduced a little by the presence of BF, but DTT shows that both tensile strength and elongation are improved by BF. Considering that DTT is more performance related, DTT is preferred over BBR to evaluate cracking potentials at low temperatures of asphalt binder modified with CR and BF. Finally, it is revealed through microscale scanning that three mechanisms, absorption of asphalt binder, 3-dimensional fiber network, and bridging effects, contribute to the performance improvement of asphalt binder modified with CR and BF.
\end{abstract}

\section{Introduction}

With rapid development of human society and resultant fast growing of various kinds of wastes, the application of engineering waste to infrastructure has been gaining attention in both academic and engineering aspects $[1,2]$. The use of crumb rubber to modify asphalt has a long history and continues to receive great attention. At least two benefits motivated the development of crumb rubber (CR) modified asphalt. Firstly, CR can enhance asphalt property and improve pavement performance, such as rutting resistance, comfortable driving, and noise reduction; secondly, it recycles waste rubber and relieves environmental pressure, e.g., consumption of scrap tire [3-11]. Basalt fiber (BF) is another common additive to improve performance of paving materials. $\mathrm{BF}$ is made of basalt rock that melted at approximately $1500^{\circ} \mathrm{C}$. It has very good performance in terms of modulus, strength, stability, and durability $[12,13]$. In recent decades, BF has been successfully used in asphalt mixture to help improve rutting and cracking distresses [14-23]. Although a lot of research has been dedicated to augment asphalt material property by adding $\mathrm{CR}$ or $\mathrm{BF}$ separately, there are few studies on performance evaluation of asphalt material modified with both CR and BF. In this study, BF was added to asphalt binder modified by CR, followed by a comprehensive laboratory evaluation of this compositely modified asphalt binder.

The research is based on a highway project planned in Inner Mongolia in northern China, where the winter is longer than 6 months with average temperature of $-20^{\circ} \mathrm{C}$. Summer is short, but the diurnal temperature difference is huge; the daytime temperature can reach $43^{\circ} \mathrm{C}$, while midnight temperature falls below $10^{\circ} \mathrm{C}$. Another concern is the reality that Inner Mongolia is one of the most important mineral resource areas in China. Hauling trucks with heavy load, especially for coal transport, account for a large portion of the traffic (70\%). Axial load can be as high as $140 \mathrm{kN}, 40 \%$ higher than the regulated load $(100 \mathrm{kN})$ in China. And 
contact pressure is generally between 1.0 and 1.4 MPa well above the standard pressure of $0.7 \mathrm{MPa}$. The original plan for this highway project was to build a CR modified asphalt pavement because of the aforementioned merits of crumb rubber. But with such extreme situations of combined excessive traffic load and harsh environmental conditions, there are raised concerns about the robustness of the asphalt pavement. To further improve the performance of CR modified asphalt pavement, this research was conducted to seek for the possibility of adding BF to CR modified asphalt binder. A series of laboratory tests were conducted to evaluate the properties of CR modified asphalt binder reinforced with BF. Properties related to pavement performance including viscosity, rheological property, rutting resistance at high temperature, thermal cracking resistance at low temperature, fatigue, and shear strength were tested. The mechanism of performance improvement of BF in CR modified asphalt binder is discussed after microscale electronic scanning. The following sections present the material properties and test equipment, followed by test process, and results and discussions.

\section{Materials and Methodology}

The selected base asphalt was A-70 (asphalt with penetration 70). The physical properties are listed in Table 1. The filler (particles below $0.075 \mathrm{~mm}$ ) is made of limestone with a density of $2.638 \mathrm{~g} / \mathrm{cm}^{3}$. Short basalt fiber and 40 -mesh crumb rubber were chosen to modify the asphalt. Table 2 lists the physical and mechanical property of basalt fiber, and Table 3 shows the major ingredients of crumb rubber.

2.1. RTFOT: Rolling Thin-Film Oven Test. The sample preparation consists of two steps. Firstly, crumb rubber and filler were introduced to asphalt to prepare CR modified asphalt binder [32]. Then, different dosages of BF were added and manually blended into the CR modified asphalt binder. The preparation process is illustrated in Figure 1. The final asphalt binder contains both $\mathrm{CR}$ and $\mathrm{BF}$ and is termed as CR-BF asphalt binder.

The remaining part of this section introduces the main information about test equipment and methodologies for the laboratory tests. The specific information related to test procedure, sample size, and calculation process of each test is described with results in the next section. Four replicates are tested for each test, and average values are used for analysis.

A dynamic shear rheometer (DSR, Figure 2(a)), Physica MCR 301, was employed to characterize the viscosity and rheological property of asphalt material including complex shear modulus $G *$ and phase angle $\delta[33,34]$. Viscosity is a primary measurement to evaluate asphalt binder's overall performance. $G *$ represents material's total resistance to deformation, and $\delta$ represents the elasticity-viscosity ratio of material. The DSR test uses a thin asphalt sample (Figure 2(b)) sandwiched between two circular plates. The lower plate is fixed, while the upper plate oscillates or rotates. The size of sample is dependent on test temperature and material's property. From the rheological property of $G *$ and $\delta$, rutting factor $G * / \sin \delta$ and fatigue factor $G * \sin \delta$ can be obtained to investigate the rutting resistance at high temperature and fatigue property of asphalt binder.

The bending beam rheometer (BBR, Figure 3(a)) test exerts a three-point bending to an asphalt beam (Figure 3(b)) at temperature below zero to evaluate ductility of asphalt material at low temperature. It provides a measurement of creep stiffness $S$ and relaxation rate $m$-value of samples [35]. These parameters give an indication of low temperature cracking potential. Direct tension test (DTT, Figure $4(\mathrm{a})$ ) is a complementary test to evaluate low temperature cracking resistance when $S$ in the BBR test is not satisfactory, especially for modified asphalt material $[36,37]$. It pulls a dog bone shape specimen at a constant elongation rate (Figure $4(\mathrm{~b})$ ). The final elongation (failure strain) and strength (failure stress) are recorded to evaluate low temperature performance.

To directly evaluate the shear behavior of asphalt binder, a cone penetration test was designed based on the traditional penetration test for asphalt binder by replacing the steel needle with a steel cone head, plus extra weight (Figure 5). The penetration depth is recorded for calculation of shear strength.

Finally, the samples failed at DTT were scanned by environmental scanning electron microscope (SEM, Figure 6) to detect the state of BF in the CR-BF asphalt binder in microscale. The microscale image would help explain the mechanism of reinforcement of $\mathrm{BF}$ in the $\mathrm{CR}-\mathrm{BF}$ asphalt binder.

\section{Results and Discussions}

3.1. Viscosity. Viscosity is a key factor reflecting the overall performance of asphalt binder including stiffness, temperature sensitivity, and adhesion with aggregates. In general, asphalt binder with higher viscosity has better shear deformation resistance and better bond with aggregates. The viscosity was tested by DSR in Rotational Mode at rate of $10 \mathrm{rad} / \mathrm{s}$, from $50^{\circ} \mathrm{C}$ to $175^{\circ} \mathrm{C}$ with increment of $2^{\circ} \mathrm{C} / \mathrm{min}$ [33]. The sample was $25 \mathrm{~mm}$ in diameter and $1 \mathrm{~mm}$ thick. Viscosities of samples with different BF contents are plotted in semilogarithm scale chart (Figure 7). It shows that as temperature rises, viscosity of all samples decreases. But samples with higher BF contents demonstrate higher viscosity. $60^{\circ} \mathrm{C}$ and $135^{\circ} \mathrm{C}$ are usually chosen to evaluate viscosity of asphalt material, for they correspond to the typical surface temperature in summer and temperature during construction, respectively. Viscosity at $60^{\circ} \mathrm{C}$ and $135^{\circ} \mathrm{C}$ is listed in Table 4. As BF increases, the viscosity of asphalt binder increases at a decreasing rate. When $\mathrm{BF}$ increases from $0 \%$ to $0.2 \%$, viscosity at $60^{\circ} \mathrm{C}$ and $135^{\circ} \mathrm{C}$ is increased by $23.9 \%$ and $33.3 \%$, respectively. At the same time, increment of $\mathrm{BF}$ from $0.3 \%$ to $0.4 \%$ only increases viscosity at $60^{\circ} \mathrm{C}$ and $135^{\circ} \mathrm{C}$ by $7.7 \%$ and $5.7 \%$, respectively.

3.2. Rheological Property. When in service, pavement is subjected to varying loading and surrounding environmental conditions. Rheological property of asphalt binder 
Table 1: Properties of base asphalt (A-70).

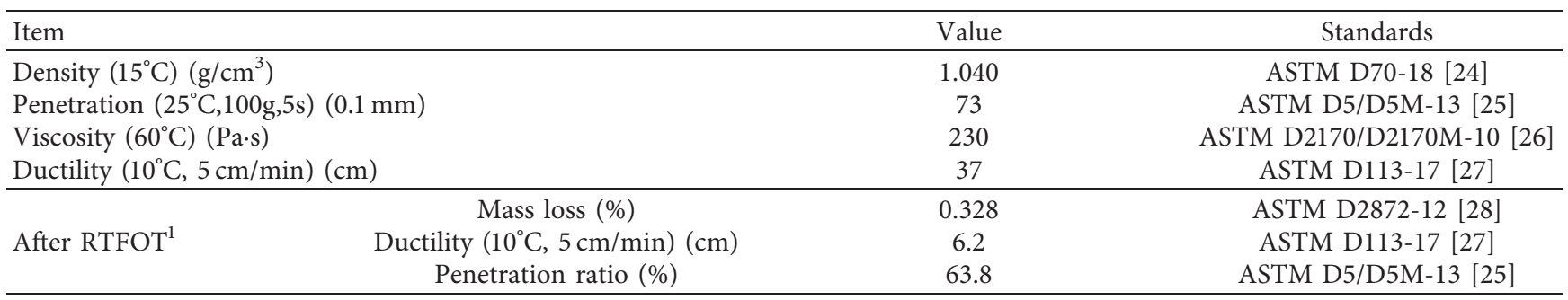

TABle 2: Physical and mechanical properties of basalt fiber.

\begin{tabular}{lcc}
\hline Item & Value & Standards \\
\hline Density $\left(\mathrm{g} / \mathrm{cm}^{3}\right)$ & $2.56 \sim 3.05$ & ASTM D3800-16 [29] \\
\hline Diameter $(\mu \mathrm{m})$ & 13 & ASTM D204-16 [29] \\
Length $(\mathrm{mm})$ & 6 & \\
\hline Tensile strength $(\mathrm{MPa})$ & $4100 \sim 4830$ & \\
Elastic modulus $(\mathrm{GPa})$ & $90 \sim 110$ & ASTM D5034-17 [30] \\
Elongation rate $(\%)$ & $3.0 \sim 3.3$ & \\
\hline
\end{tabular}

TABle 3: Compounds of crumb rubber.

\begin{tabular}{lcc}
\hline Item & Percent material (\%) & Standards \\
\hline Carbon black & 34.8 & \\
Extractables & 11.4 & ASTM E1131-14 [31] \\
Polymer & 50.3 & \\
Ash & 3.1 & \\
\hline
\end{tabular}

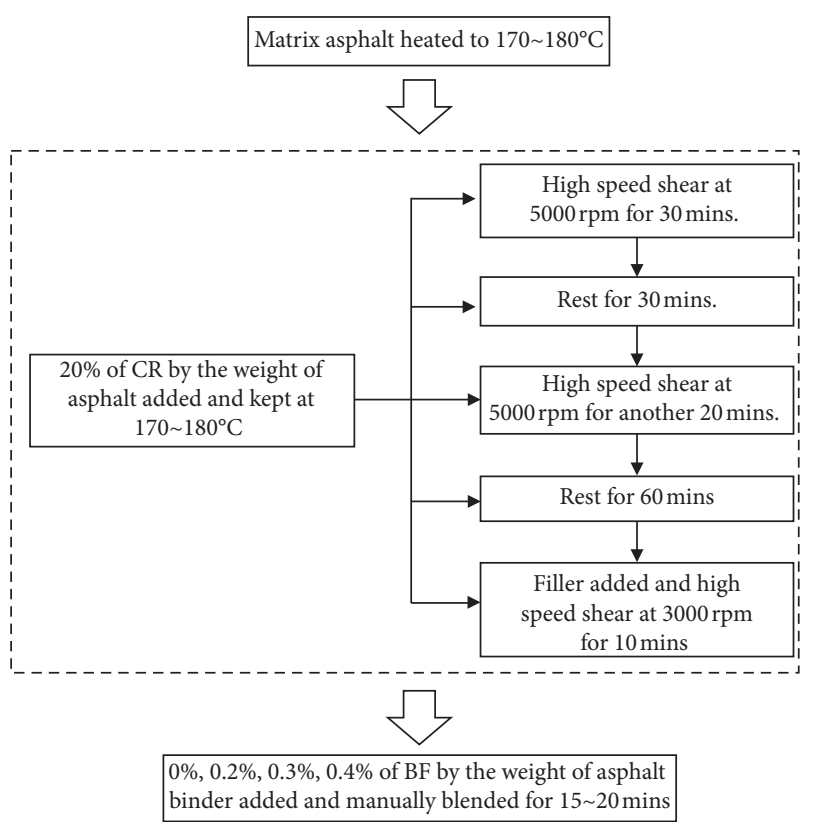

Figure 1: Scheme of CR-BF asphalt binder preparation.

accounts for the resistance to both load and temperature change. By temperature sweeping test on samples, the relationship of rheological property $\left(G^{*}\right.$ and $\left.\delta\right)$ with temperature was studied. The test was conducted by DSR under Oscillation Mode at frequency of $10 \mathrm{rad} / \mathrm{s}$, angular amplitude $12 \%$, and heating rate $2^{\circ} \mathrm{C} / \mathrm{min}$ from $50^{\circ} \mathrm{C}$ to $80^{\circ} \mathrm{C}$ [34]. The sample was $25 \mathrm{~mm}$ in diameter and $1 \mathrm{~mm}$ thick. Results are plotted in Figure 8, including complex shear modulus $G^{*}$, phase angle $\delta$, storage shear modulus $G^{\prime}$, and loss shear modulus $G^{\prime \prime}$. Specifically, $G^{\prime}$ and $G^{\prime \prime}$ represent the elastic property and viscous property, respectively. Relations between $G^{*}, G^{\prime}, G^{\prime \prime}$, and $\delta$ are shown in equations (1) (2).

$$
\begin{aligned}
& \left|G^{*}\right|=\sqrt[2]{(G \prime)^{2}+\left(G^{\prime \prime}\right)^{2}}, \\
& \tan \delta=\frac{\left|G^{\prime \prime}\right|}{\left|G^{\prime}\right|} .
\end{aligned}
$$

It is clearly shown that $G^{*}$ deceases, while $\delta$ increases with temperature. With BF content increasing, $G^{*}$ increases and $\delta$ decreases, indicating that the addition of BF makes asphalt binder stiffer and more elastic. In Figure 8(b), when BF increases from $0.2 \%$ to $0.3 \%$, this is a sudden drop in $\delta$; correspondently, $G^{\prime}$ in Figure 8(c) sees a similar sudden jump, whilst Figure 8(d) for $G^{\prime \prime}$ shows a small and steady increase with $\mathrm{BF}$ content. Based on the relationships shown in equations $(1) \sim(2)$, it can be concluded that BF actually increases both $G^{\prime}$ and $G^{\prime \prime}$, resulting in increased $G^{*}$, shown in Figure 8(a). But the increase in G' (Figure 8(c)) is much more significant than in $G^{\prime \prime}$ (Figure $8(\mathrm{~d})$ ), causing a decreasing $\delta$ with $\mathrm{BF}$ content. In other words, elastic property $\left(G^{\prime}\right)$ is more sensitive to the existence of BF.

From the rheologic parameters of $G^{*}$ and $\delta$, we can evaluate rutting resistance and fatigue resistance of CR-BF asphalt binder. When under high temperature and heavy load, rutting can easily develop. The odds and developing rate of rutting is closely related to permanent deformation resistance of asphalt binder. When work is done to asphalt pavement (or asphalt material), part of the work $W_{c}$ is dissipated to cause permanent deformation (unrecoverable deformation) and cracking, accompanied with heat. $W_{c}$ can be calculated by

$$
W_{c}=\pi \sigma \varepsilon \sin (\delta) \text {. }
$$

For a given stress level $\sigma_{0}$,

$$
\varepsilon=\frac{\sigma_{0}}{G^{*}} \text {. }
$$

Replace $\varepsilon$ in equation (3) with equation (4),

$$
W_{c}=\frac{\pi \sigma_{0}^{2}}{G^{*} / \sin (\delta)},
$$

where $W_{c}$ is dissipated energy, $\sigma$ is stress, $\varepsilon$ is strain, and $\delta$ is phase angle. 


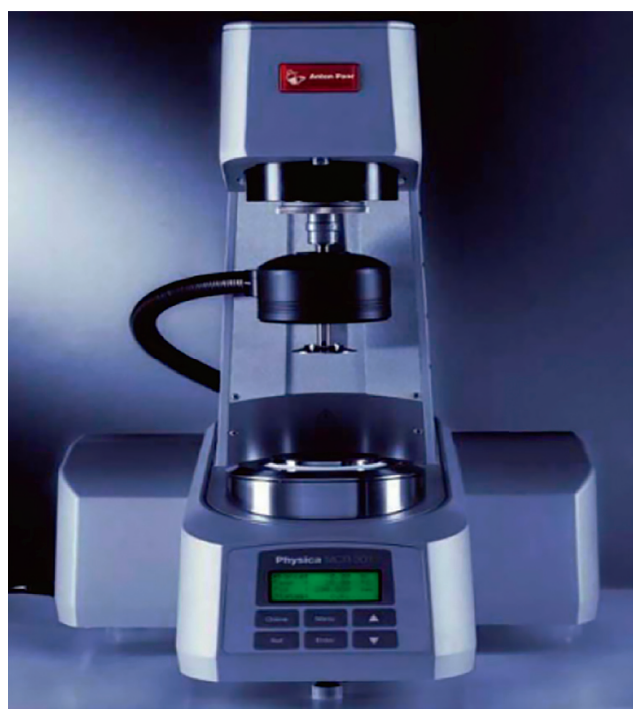

(a)

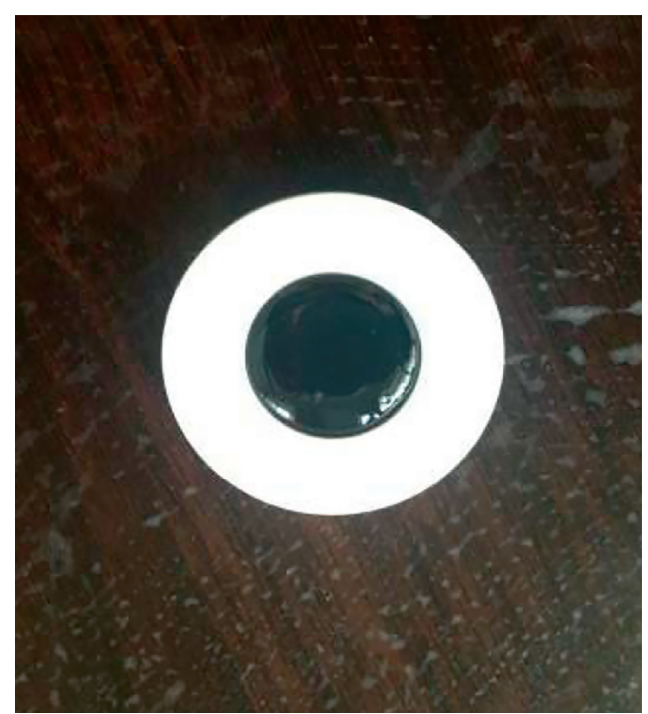

(b)

Figure 2: DSR test. (a) Physica MCR 301(Anton Paar). (b) Test sample.

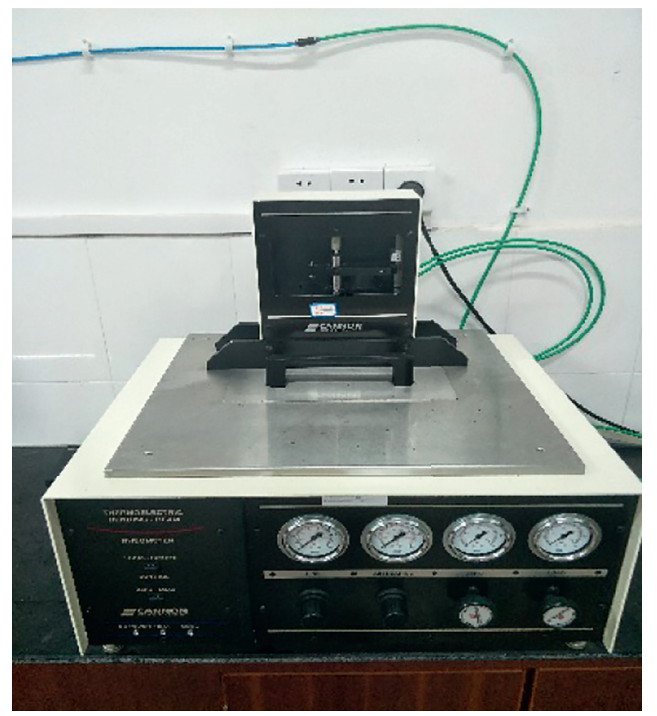

(a)

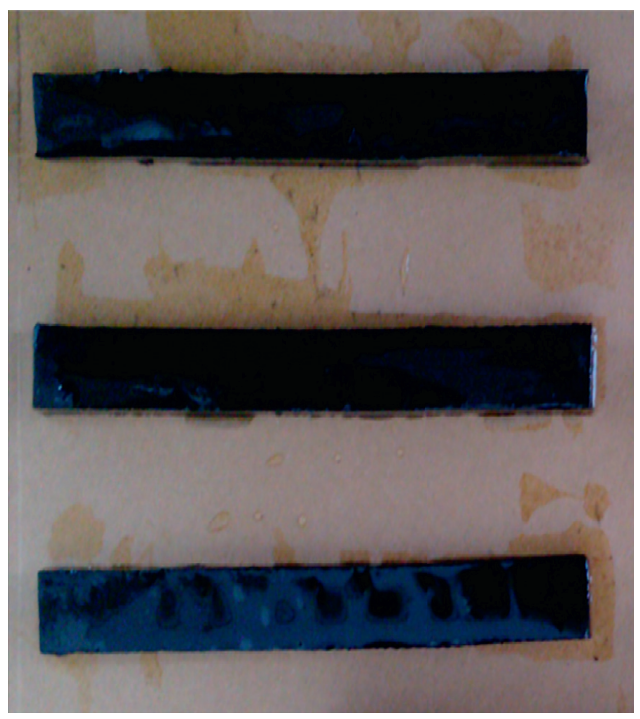

(b)

Figure 3: BBR test. (a) BBR equipment (CANNON). (b) Test specimen.

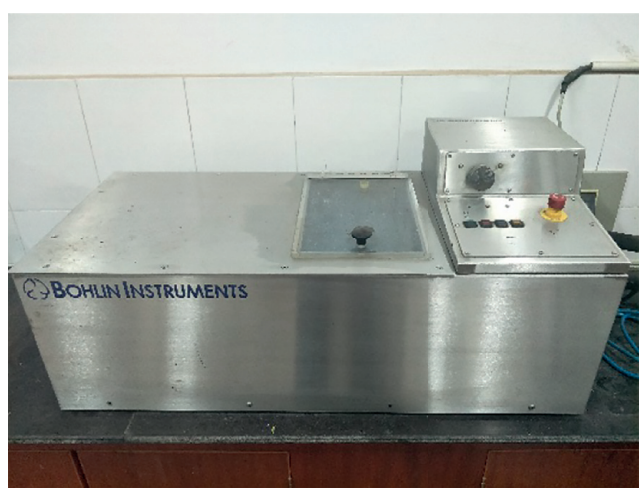

(a)

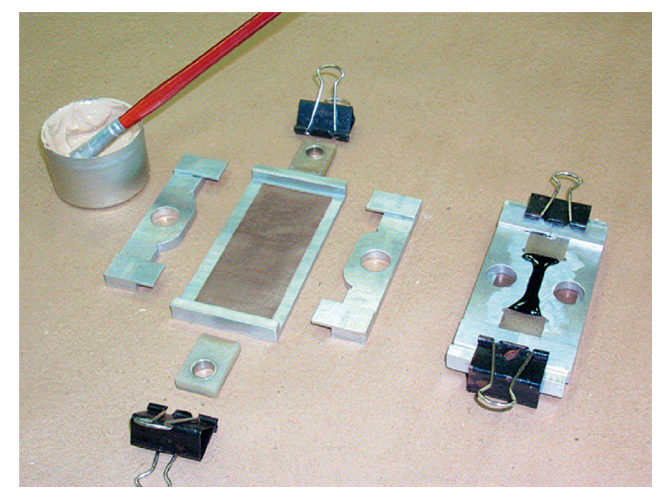

(b)

Figure 4: DTT test. (a) DTT equipment (American Interlaken). (b) Test sample. 


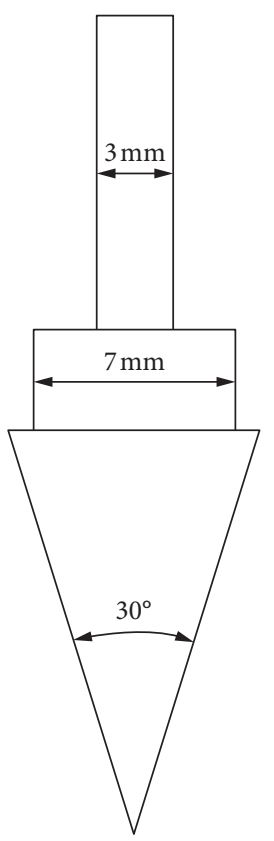

(a)
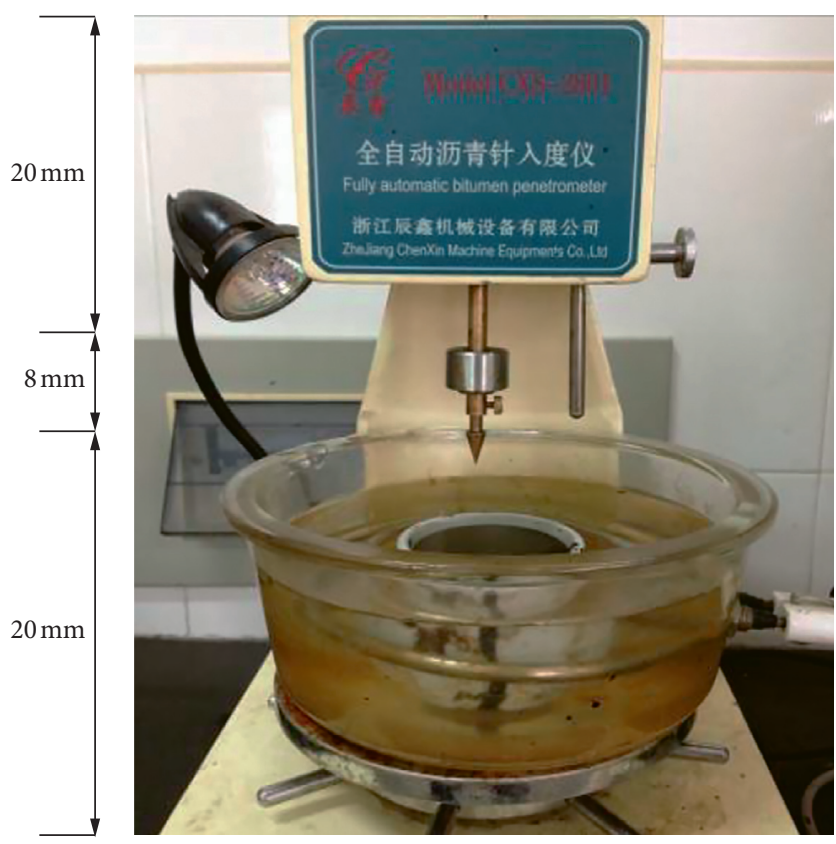

(b)

Figure 5: Cone penetration shear test. (a) Sketch of the cone head. (b) Instrument and sample.

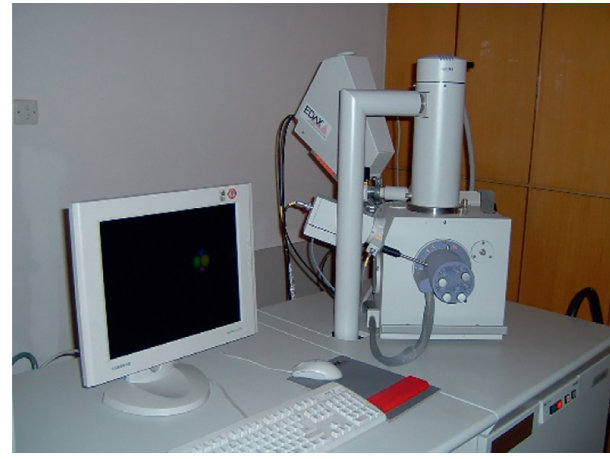

Figure 6: Sem (Hitachi limited, S-3000N).

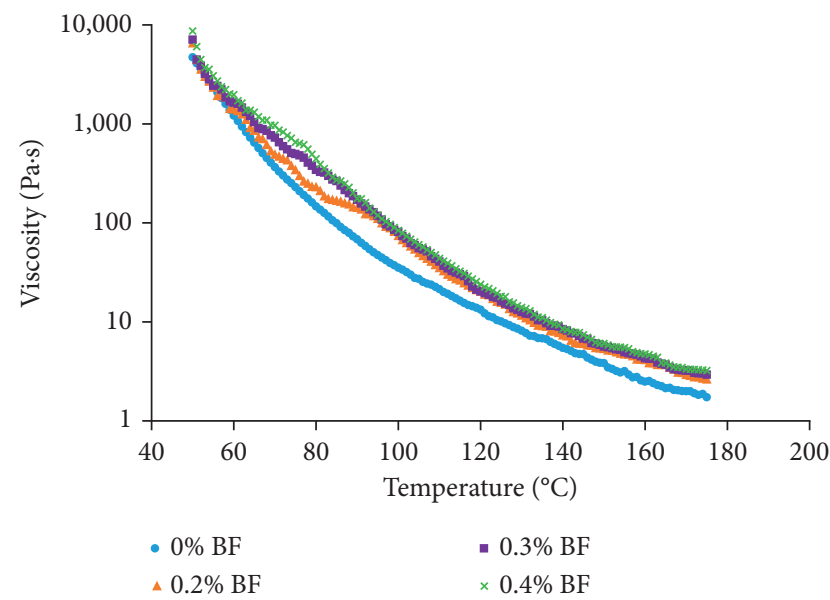

Figure 7: Viscosity CR-BF asphalt binder of different BF contents.
TABLe 4: Viscosity of CR-BF asphalt binder at $60^{\circ} \mathrm{C}$ and $135^{\circ} \mathrm{C}$.

\begin{tabular}{lcc}
\hline BF content (\%) & Viscosity at $60^{\circ} \mathrm{C}(\mathrm{Pa} \cdot \mathrm{s})$ & Viscosity at $135^{\circ} \mathrm{C}(\mathrm{Pa} \cdot \mathrm{s})$ \\
\hline 0 & 1210 & 6.81 \\
0.2 & 1500 & 9.08 \\
0.3 & 1680 & 10.4 \\
0.4 & 1810 & 11.0 \\
\hline
\end{tabular}

As shown is equation (5), rutting factor $G^{*} / \sin (\delta)$ is reversely proportioned to $W_{c}$ and, thus, can be used to evaluate the permanent deformation resistance of asphalt binder. When asphalt binder is stiffer (higher $G^{*}$ ) and more elastic (smaller $\delta$ ), the resistance to rutting is better. Rutting factors were tested above $58^{\circ} \mathrm{C}$ with increment of $6^{\circ} \mathrm{C}$ using DSR. The sample was $25 \mathrm{~mm}$ in diameter and $1 \mathrm{~mm}$ thick [34]. Results in Table 5 show that as BF content increases, rutting factor increases, indicating that the addition of $\mathrm{BF}$ improves permanent deformation resistance. This improvement is more prominent at higher temperatures. The specification of asphalt material performance grade (PG) requires $G^{*} / \sin (\delta)$ to be above $1 \mathrm{kPa}$ [38]. Apparently, the addition of $0.2 \%$ and $0.4 \%$ of BF increases asphalt binder from PG 82 to PG 88 and PG 94, respectively.

Fatigue cracking is another common distress in flexible pavement. As mentioned before, part of the work done by traffic is dissipated and intrigues fatigue cracking. Generally, there are two modes of fatigue; one is stress control and the other is strain control. The strain control mode simulates the condition in thin asphalt layer, which is more prevailing in fatigue cracking distress.

For a given strain level $\varepsilon_{0}$

$$
\sigma_{0}=\varepsilon_{0} G^{*} \text {. }
$$




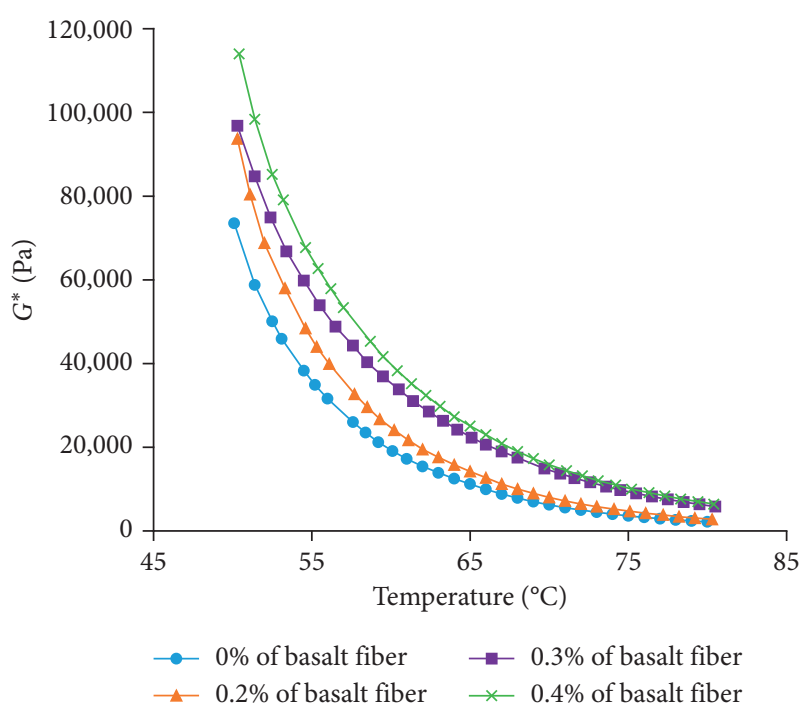

(a)

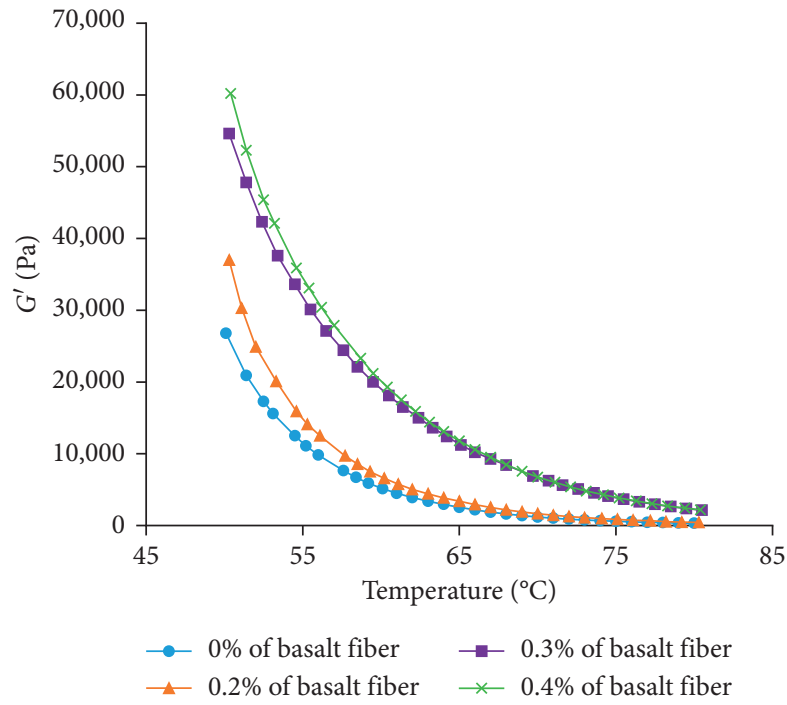

(c)

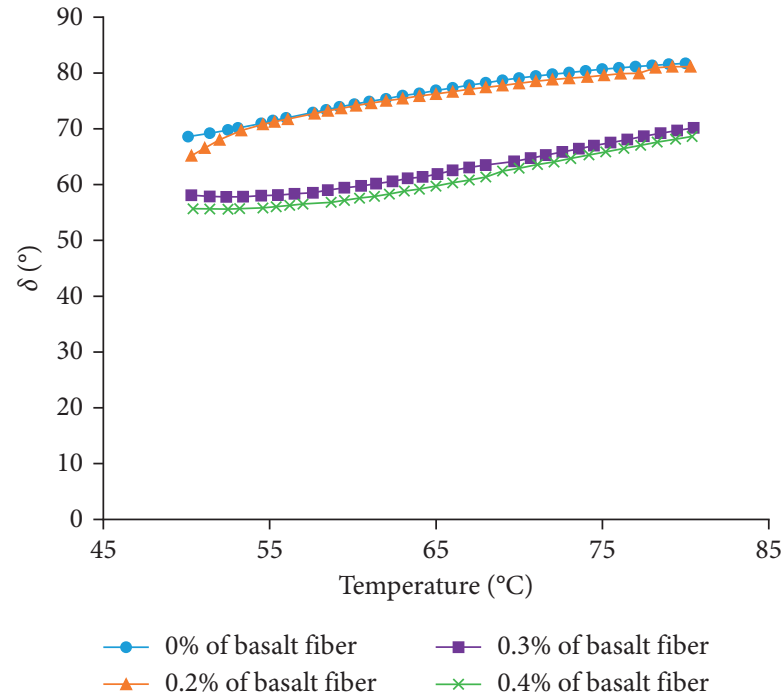

(b)

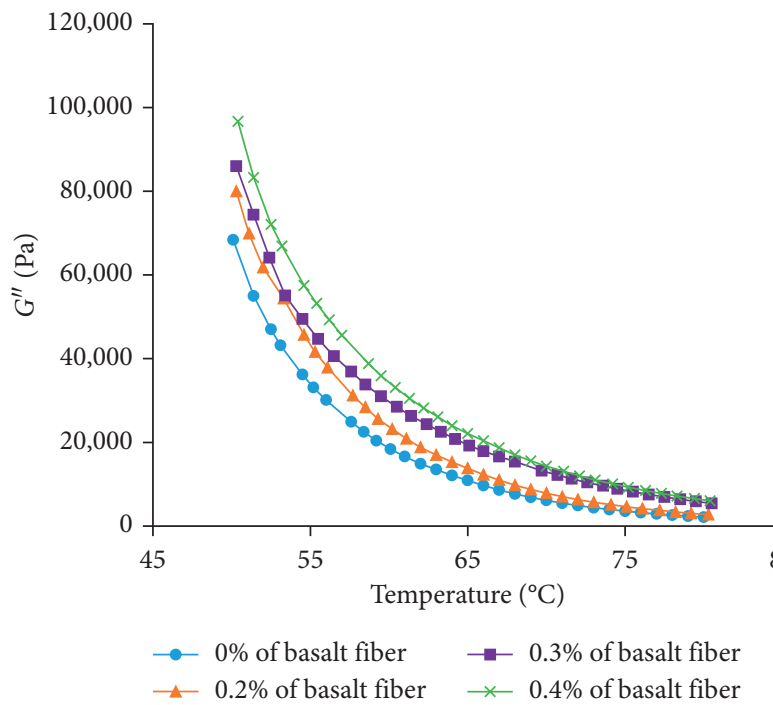

(d)

Figure 8: Rheological property. (a) Complex shear modulus $G^{*}$. (b) Phase angle $\delta$. (c) Storage shear modulus $G^{\prime}$. (d) Loss shear modulus $G^{\prime \prime}$.

TABLE 5: Rutting factor $G^{*} / \sin (\delta)(\mathrm{kPa})$.

\begin{tabular}{lcccccccc}
\hline $\begin{array}{l}\text { BF content } \\
(\%)\end{array}$ & 58 & 64 & 70 & 76 & 82 & 88 & 94 & 100 \\
\hline 0 & 30.31 & 12.45 & 6.19 & 3.35 & 1.67 & 0.81 & - & \\
0.2 & 35.00 & 16.71 & 9.66 & 4.60 & 2.20 & 1.03 & 0.47 & - \\
0.3 & 56.83 & 28.44 & 16.36 & 7.99 & 3.98 & 1.81 & 0.91 & - \\
0.4 & 67.92 & 32.63 & 20.33 & 10.60 & 5.19 & 2.57 & 1.21 & 0.58 \\
\hline
\end{tabular}

replace $\sigma$ in equation (3) with equation (6):

$$
W_{c}=\pi \varepsilon_{0}^{2}\left(G^{*} \cdot \sin (\delta)\right) \text {. }
$$

In equation (7), dissipated energy $W_{C}$ is positively related to fatigue factor $G^{*} / \sin (\delta)$. As a result, $G^{*} / \sin (\delta)$ is used as an index to evaluate the fatigue property of asphalt binder. Larger $G^{*} / \sin (\delta)$ means more energy is dissipated to cause damage. The results from DSR are plotted in Figure 9. Generally speaking, the $G^{*} / \sin (\delta)$ of asphalt material is required to be less than $5000 \mathrm{kPa}$ in specification, marked as the grey horizontal dash line in Figure 9 [38]. The test started from higher temperature to lower temperature with decrement of $3^{\circ} \mathrm{C}$. The sample for fatigue evaluation is $8 \mathrm{~mm}$ in diameter and $2 \mathrm{~mm}$ thick.

As more $\mathrm{BF}$ is added, fatigue factor $G * \sin \delta$ increases, indicating that the addition of $\mathrm{BF}$ increases fatigue factor $G^{*} / \sin (\delta)$; however, the change is not significant. Given the requirement of $G^{*} / \sin (\delta) \leq 5000 \mathrm{kPa}$, the design temperature for all samples with different BF contents is still at the same level $\left(22^{\circ} \mathrm{C}\right)$. However, it is important to keep in mind that the evaluation of $G^{*} / \sin (\delta)$ for fatigue is not performance based. Bigger $G^{*} / \sin (\delta)$ just indicates higher potential of fatigue cracking, but not necessarily increases fatigue cracking in real situation. In fact, the causes of fatigue cracking are more comprehensive and complicated than just the asphalt material property. 


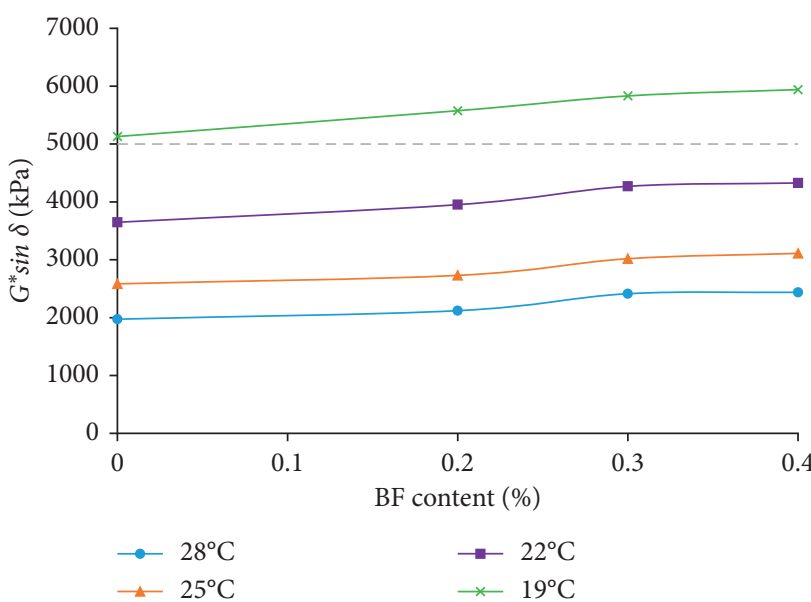

FIGURE 9: Fatigue property results.

3.3. Low Temperature Cracking Resistance. As environmental temperature drops, the body of pavement would contract and internal stress builds up. If this contraction occurs fast enough, tensile stress accumulates in asphalt concrete and may cause cracking. To avoid low temperature cracking, the asphalt binder is required to either relax fast to release the stress or be strong enough to resist the stress. The BBR test is a method to investigate the creep stiffness at low temperature. The test specimen is an asphalt beam with a dimension of $6.25 \times 12.5 \times 127 \mathrm{~mm}$ (thickness $\times$ width $\times$ length), and the three-point loading of $980 \mathrm{mN} \pm 50 \mathrm{mN}$ is applied to the specimen for $240 \mathrm{~s}$ [34]. The test result includes two parts: creep stiffness $S$ and slope of response $m$-value. $S$ and $m$-value after loading for $60 \mathrm{~s}$ were used to determine the low-temperature PG. The specification requires $S$ to be no more than $300 \mathrm{MPa}$, and $m$ value to be no less than 0.3 [35]. Test temperature started at $-6^{\circ} \mathrm{C}$, with a decrement of $6^{\circ} \mathrm{C}$. The results listed in Table 6 show that as BF content increases, $S$ increases and $m$-value decreases. This is an indication that BF makes the asphalt binder stiffer. Another way to check the low temperature performance is the direct tensile test (DTT), which determines the tensile strength at low temperature. DTT is conducted at rate of $1.0 \mathrm{~mm} / \mathrm{min}$ until the sample fails [36]. Elongation (failure strain) and strength (failure stress) are recorded. Specification requires the elongation be no less than $1 \%$ [37]. One thing to note is that failure criteria of DTT are defined as the load when stress reaches its maximum value, not when the specimen breaks. It can be seen From Table 6 that all specimens in the BBR test fail $(S \geq 300 \mathrm{MPa}$ or $m \leq 0.3)$ at $-18^{\circ} \mathrm{C}$. To check the strength and elongation at $-18^{\circ} \mathrm{C}$, DTT were conducted at $-18^{\circ} \mathrm{C}$ and the results are listed in Table 7. As shown, the addition of BF increases both elongation and strength. The maximum failure strength and failure strain are achieved at $0.3 \% \mathrm{BF}$.

The BBR test shows that the addition of BF downgraded ductility asphalt beam at low temperature. This is not surprising, given the above rheological property results that $\mathrm{BF}$ increases $G^{*}$ and $G^{\prime}$ : when BF increases $G *$, especially $G^{\prime}$, asphalt binder becomes stiffer, resulting in bigger $S$ values.
TABLE 6: BBR results.

\begin{tabular}{lcccccc}
\hline \multirow{2}{*}{ BF content(\%) } & \multicolumn{2}{c}{$-6^{\circ} \mathrm{C}$} & \multicolumn{2}{c}{$-12^{\circ} \mathrm{C}$} & \multicolumn{2}{c}{$-18^{\circ} \mathrm{C}$} \\
& $S(\mathrm{MPa})$ & $m$ & $S(\mathrm{MPa})$ & $m$ & $S(\mathrm{MPa})$ & $m$ \\
\hline 0 & 72.6 & 0.505 & 161 & 0.398 & 498 & 0.275 \\
0.2 & 92.1 & 0.488 & 174 & 0.343 & 553 & 0.259 \\
0.3 & 97 & 0.428 & 223 & 0.340 & 547 & 0.264 \\
0.4 & 98.5 & 0.429 & 284 & 0.336 & 552 & 0.287 \\
\hline Specification & \multicolumn{6}{c}{$S \leq 300 \mathrm{MPa}, m \geq 0.3$} \\
\hline
\end{tabular}

TABLE 7: DTT results at $-18^{\circ} \mathrm{C}$.

\begin{tabular}{lcc}
\hline BF content $(\%)$ & Failure strength $(\mathrm{MPa})$ & Failure strain $(\%)$ \\
\hline 0 & 2.45 & 0.25 \\
0.2 & 2.98 & 1.87 \\
0.3 & 3.10 & 2.66 \\
0.4 & 2.71 & 1.65 \\
\hline
\end{tabular}

Another reason is that the existence of BF works like a reinforcement in the beam (compared to steel bar in concrete beam) and decreases the deflection of the asphalt beam for a given load in BBR, showing less ductility. However, the development of thermal cracking is not only related to ductility but also to tensile strength of material. Although the existence of BF may decrease ductility on one hand, it may also enhance tensile strength and increase thermal cracking resistance on the other. DTT results confirm this, showing that asphalt binder with $\mathrm{BF}$ has not only higher tensile strength but also larger elongation. One thing to note is that, in DTT, samples are tested until maximum stress or fail, whereas the load in BBR is quite limited. For this reason, the results of DTT are more convincing for asphalt binder modified with BF as DTT is performance related.

3.4. Shear Strength. A lot of distresses of asphalt pavement are related to shear failure in asphalt mixture. To directly test the shear behavior of CR-BF asphalt binder, a cone penetration test was designed and conducted. The cone weighs $50 \mathrm{~g}$ with an angle $\alpha=30^{\circ}$, with an extra weight of $100 \mathrm{~g}$ added. Test sample was poured into a vessel and kept in water bath at $40^{\circ} \mathrm{C}$ for 2 hours. After that, the cone head was released and penetrated into the surface of the sample. The penetration depth at which the cone head stayed stable for at least $10 \mathrm{~s}$ was recorded to calculate the shear strength, as equation (8) shows.

$$
\tau=\frac{G \cos ^{2}(\alpha / 2)}{\pi h^{2} \tan (\alpha / 2)},
$$

where $\tau$ is shear strength, $G$ is the total weight of the cone and additional weight $(N), \alpha$ is cone angle $\left(^{\circ}\right)$, and $h$ is penetration depth $(0.1 \mathrm{~mm})$.

As listed in Table 8, the shear strength sees a steady increase from $18.8 \mathrm{kPa}$ to $40.2 \mathrm{kPa}$ when $\mathrm{BF}$ increases from 0 to $0.4 \%$. Especially when $\mathrm{BF}$ increases from $0.2 \%$ to $0.3 \%$, the increase of shear strength is nearly $30 \%$. Cone penetration test gives a direct measurement of shear strength. It is obvious that the CR-BF asphalt binder with more BF has higher shear strength. 
Table 8: Cone penetration test results.

\begin{tabular}{lcc}
\hline BF content $(\%)$ & Penetration $(0.1 \mathrm{~mm})$ & Shear strength $(\mathrm{kPa})$ \\
\hline 0 & 93.1 & 18.8 \\
0.2 & 81.2 & 24.7 \\
0.3 & 71.8 & 33.2 \\
0.4 & 63.7 & 40.2 \\
\hline
\end{tabular}

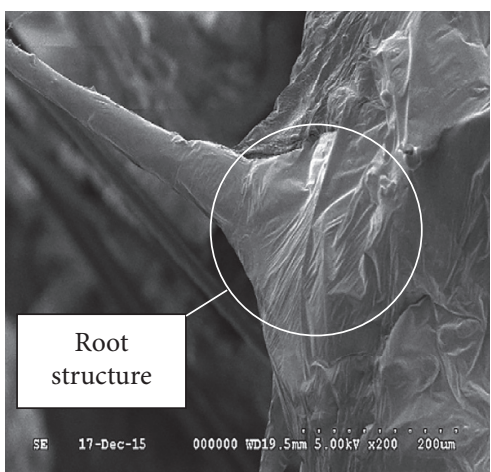

$200 \mu \mathrm{m}$

(a)

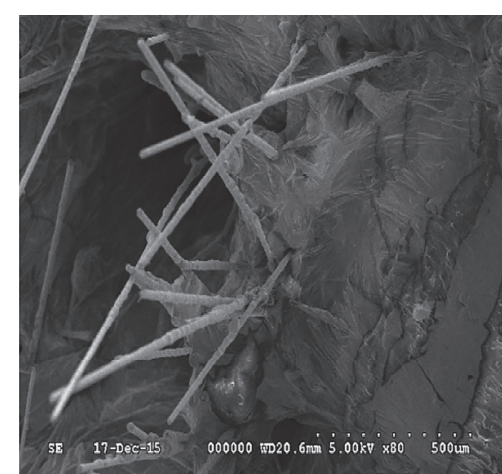

$500 \mu \mathrm{m}$

(b)

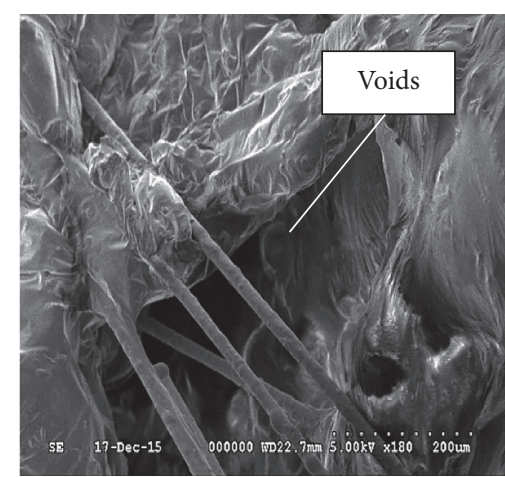

$200 \mu \mathrm{m}$

(c)

FIGURE 10: Scanning by SEM. (a) Saturated BF surface with asphalt binder. (b) Distribution of BF in asphalt binder. (c) Bridging over voids.

3.5. Microscale Scanning by SEM. Samples that failed the DTT were collected and scanned under the SEM to detect the state of $\mathrm{BF}$ in asphalt binder in microscale observation. Figure 10(a) shows that asphalt binder is absorbed by BF and root structure forms at the foot of BF. Figure 10(b) demonstrates the distribution of $\mathrm{BF}$ in asphalt binder: the fiber is dispersed in random direction and forms an interacted three-dimensional network, which can act as a reinforcement. In Figure 10(c), BF bridges over a void area (e.g., damage surface) via the root structures and interconnected separated parts together.

The scanned microscale image helps explain the reinforcement mechanism of $\mathrm{BF}$ in $\mathrm{CR}-\mathrm{BF}$ asphalt binder. Firstly, BF absorbs asphalt binder. As the asphalt molecules align near the internal and external surface of BF filament, they increase the thickness of asphalt membrane and effectively increase the adhesion between asphalt binder and $\mathrm{BF}$ [12]. As a result, the cohesion of asphalt binder near the BF-asphalt interface is increased, causing higher viscosity, shear modulus, and elasticity, which in turn decreases temperature sensitivity, improves deformation resistance at high temperature, and increases shear strength. At the same time, root structures form at the foot of $\mathrm{BF}$ and would further enhance the adhesion between BF and asphalt binder. Secondly, the BF forms a randomly interacted threedimensional network in the asphalt binder. As BF has very high modulus and strength, the fiber network would help transfer stress and increase stiffness (deformation resistance) and tensile strength of asphalt binder, like the reinforcing steel bars in concrete. Thirdly, this reinforcement of BF is even more obvious when damage is already induced in asphalt binder. BF would bridge across the damage surface and connect the separated parts together. This indicates that
BF can effectively retard cracking propagation and increase the service life of asphalt binder. Of course all the aforementioned effects are dependent on the amount of BF. Too little $\mathrm{BF}$ is not enough to form a sufficient network, while excessive $\mathrm{BF}$ is hard to disperse in asphalt binder and would degrade the interaction between $\mathrm{BF}$ and asphalt binder. As such, the performance or changing rate of performance varies with $\mathrm{BF}$ content. Overall, the optimal $\mathrm{BF}$ content is $0.3 \%$ by the weight of asphalt binder in this study, at which the $G^{*}$ and shear strength experience a fastest growth and tensile strength is the highest in DTT.

\section{Conclusions}

Different dosages of BF were introduced to $\mathrm{CR}$ modified asphalt binder to make a hybrid modified CR-BF asphalt binder. Samples were tested in multiple ways to evaluate its property and performance under the SHRP evaluation system. Overall, the addition of BF enhances the performance of asphalt binder. Main conclusions can be drawn:

(1) BF increases viscosity of CR modified asphalt binder at a decreasing rate. The addition of $0.2 \% \mathrm{BF}$ increases $23.9 \%$ and $33.3 \%$ of viscosity at $60^{\circ} \mathrm{C}$ and $135^{\circ} \mathrm{C}$, respectively. It also increases dynamic complex shear modulus $G^{*}$ and decreases phase angle $\delta$. The influence of BF on elastic property is more significant. Although $G^{*}$ keeps increasing with BF, the growing speed slows down after a big jump at $0.3 \% \mathrm{BF}$.

(2) The existence of BF increases rutting factor $G^{*} / \sin (\delta)$ significantly, indicating better rutting resistance at high temperatures. The addition of $0.2 \%$ 
and $0.4 \%$ of BF increases asphalt binder from PG 82 to PG 88 and PG 94, respectively. Cone penetration test also shows that the increased BF in asphalt binder helps get a higher shear strength. The influence of BF on fatigue factor $G^{*} / \sin (\delta)$ of asphalt binder is limited.

(3) Results ( $S$ and $m$-value) from BBR show that CR-BF asphalt binder with higher BF has less ductility at low temperature. On the other hand, DTT shows that BF increases tensile strength and elongation of CR-BF asphalt binder. The performance-related DTT is preferred to properly evaluate low temperature cracking resistance of $\mathrm{CR}-\mathrm{BF}$ asphalt binder.

(4) The SEM results uncover the state of BF in CR-BF asphalt binder. From these microscale images, it is easy to spot that absorption of asphalt binder and reinforcement of fiber network, especially "bridging" effect, lead to the property improvement of asphalt binder. The optimum BF content is $0.3 \%$ by weight of asphalt binder in this study, determined by a comprehensive evaluation of performance improvements.

\section{Data Availability}

The authors have the access of all the data, which can be provided upon request.

\section{Conflicts of Interest}

The authors declare that there are no conflicts of interest regarding the publication of this paper.

\section{Acknowledgments}

This study was funded by the National Key R\&D Program Projects of China (2018YFB1600200); National Natural Science Foundation of China (51678078); Open Fund of National Engineering Laboratory of Highway Maintenance Technology (Changsha University of Science and Technology) (kfj180101); China Scholarship Council (201608430123); and Natural Science Foundation of Hunan Province (2020JJ5578).

\section{References}

[1] J. Zhang, L. Ding, and F. Li, "Recycled aggregates from construction and demolition wastes as alternative filling materials for highway subgrades in China," Journal of Cleaner Production, vol. 255, Article ID 120223, 11 pages, 2020.

[2] J. Zhang, F. Gu, and Y. Zhang, "Use of building-related construction and demolition wastes in highway embankment: laboratory and field evaluations," Journal of Cleaner Production, vol. 230, pp. 1051-1060, 2019.

[3] X. Shu and B. Huang, "Recycling of waste tire rubber in asphalt and portland cement concrete: an overview," Construction and Building Materials, vol. 67, pp. 217-224, 2014.

[4] D. L. Presti, "Recycled tyre rubber modified bitumens for road asphalt mixtures: a literature review," Construction and Building Materials, vol. 49, pp. 863-881, 2013.
[5] S. Liu, W. Cao, J. Fang, and S. Shang, "Variance analysis and performance evaluation of different crumb rubber modified (CRM) asphalt," Construction and Building Materials, vol. 23, no. 7, pp. 2701-2708, 2009.

[6] S. Li, Y. Huang, and Z.-H. Liu, "Experimental evaluation of asphalt material for interlayer in rigid-flexible composite Pavement," Construction and Building Materials, vol. 102, pp. 699-705, 2016.

[7] D. Singh, V. Mishra, S. Girimath, A. Das, and B. Rajan, "Evaluation of rheological and moisture damage properties of crumb rubber-modified asphalt binder," Advances in Civil Engineering Materials, vol. 8, no. 1, pp. 477-496, 2019.

[8] L. You, K. Yan, D. Wang, D. Ge, and X. Song, "Use of amorphous-poly-alpha-olefin as an additive to improve terminal blend rubberized asphalt," Construction and Building Materials, vol. 228, p. 116774, 2019.

[9] K. E. Kaloush, "Asphalt rubber: performance tests and pavement design issues," Construction and Building Materials, vol. 67, pp. 258-264, 2014.

[10] F. Guo, J. Zhang, and J. Pei, "Study on the mechanical properties of rubber asphalt by molecular dynamics simulation," Journal of Molecular Modeling, vol. 25, no. 12, p. 365, 2019.

[11] X. Tan, J. Zhang, D. Guo, G. Sun, Y. Zhou, and W. Zhang, "Preparation and repeated repairability evaluation of sunflower oil-type microencapsulated filling materials," Journal of Nanoscience and Nanotechnology, vol. 20, no. 3, pp. 15541566, 2020.

[12] K. Singha, "A short review on basalt fiber," International Journal of Textile Science, vol. 1, no. 4, pp. 19-28, 2012.

[13] P. Raju, A. Verma, and H. Kumar, "Use of cyclone dust as fill material in highway construction," Advances in Civil Engineering Materials, vol. 7, no. 2, pp. 32-47, 2018.

[14] S. M. Abtahi, M. Sheikhzadeh, and S. M. Hejazi, "Fiberreinforced asphalt-concrete - a review," Construction and Building Materials, vol. 24, no. 6, pp. 871-877, 2010.

[15] D. Wang, L. Wang, X. Gu, and G. Zhou, "Effect of basalt fiber on the asphalt binder and mastic at low Temperature," Journal of Materials in Civil Engineering, vol. 25, no. 3, pp. 355-364, 2013.

[16] X. Qin, A. Shen, Y. Guo, Z. Li, and Z. Lv, "Characterization of asphalt mastics reinforced with basalt fibers," Construction and Building Materials, vol. 159, pp. 508-516, 2018.

[17] X. Zhang, X. Gu, J. Lv, and X. Zou, "3D numerical model to investigate the rheological properties of basalt fiber reinforced asphalt-like materials," Construction and Building Materials, vol. 138, pp. 185-194, 2017.

[18] F. Morea, "Study of asphalt binder's rheological properties extracted from warm mix asphalts," Advances in Civil Engineering Materials, vol. 7, no. 1, pp. 507-519, 2018.

[19] Y. Yang, Y. Zhang, E. Omairey, J. Cai, F. Gu, and A. V. Bridgwater, "Intermediate pyrolysis of organic fraction of municipal solid waste and rheological study of the pyrolysis oil for potential use as bio-bitumen," Journal of Cleaner Production, vol. 187, pp. 390-399, 2018.

[20] X. Gu, T. Xu, and F. Ni, "Rheological behavior of basalt fiber reinforced asphalt mastic," Journal of Wuhan University of Technology-Materials Science Education, vol. 29, no. 5, pp. 950-955, 2014.

[21] R. S. McDaniel, Fiber Additives in Asphalt Mixtures: a Synthesis of Highway Practice, Nchrp Synthesis 475, Transportation Research Board, Washington, DC, USA, 2015.

[22] S. Lv, C. Liu, H. Yao, and J. Zheng, "Comparisons of synchronous measurement methods on various moduli of asphalt 
mixtures," Construction and Building Materials, vol. 158, pp. 1035-1045, 2018.

[23] Y. Zheng, Y. Cai, G. Zhang, and H. Fang, "Fatigue property of basalt fiber-modified asphalt mixture under complicated environment," Journal of Wuhan University of TechnologyMaterials Science Education, vol. 29, no. 5, pp. 996-1004, 2014.

[24] ASTM D70-18, Standard Test Method for Density of Semi-solid Asphalt Binder (Pycnometer Method), ASTM International, West Conshohocken, PA, USA, 2018.

[25] ASTM D5/D5M-13, Standard Test Method for Penetration of Bituminous Materials, ASTM International, West Conshohocken, PA, USA, 2013.

[26] ASTM D2170/D2170M-10, Standard Test Method for Kinematic Viscosity of Asphalts (Bitumens), ASTM International, West Conshohocken, PA, USA, 2010.

[27] ASTM D113-17, Standard Test Method for Ductility of Asphalt Materials, ASTM International, West Conshohocken, PA, USA, 2017.

[28] ASTM D2872-12, Standard Test Method for Effect of Heat and Air on a Moving Film of Asphalt (Rolling Thin-Film Oven Test), ASTM International, West Conshohocken, PA, USA, 2012.

[29] ASTM D3800-16, Standard Test Method for Density of HighModulus Fibers, ASTM International, West Conshohocken, PA, USA, 2016.

[30] ASTM D5034-17, Standard Test Method for Breaking Strength and Elongation of Textile Fabrics (GrabTest), ASTM International, West Conshohocken, PA, USA, 2017.

[31] ASTM E1131-14, Standard Test Method for Compositional Analysis by Thermogravimetry, ASTM International, West Conshohocken, PA, USA, 2014.

[32] M. R. Pouranian, M. A. Notani, M. T. Tabesh, B. Nazeri, and M. Shishehbor, "Rheological and environmental characteristics of crumb rubber asphalt binders containing nonfoaming warm mix asphalt additives," Construction and Building Materials, vol. 238, p. 117707, 2020.

[33] ASTM D4402/4402M-15, Standard Test Method for Viscosity Determination of Asphalt at Elevated Temperatures Using a Rotational Viscometer, ASTM International, West Conshohocken, PA, USA, 2015.

[34] ASTM D7175-15, Standard Test Method for Determining the Rheological Properties of Asphalt Binder Using a Dynamic Shear Rheometer, ASTM International, West Conshohocken, PA, USA, 2015.

[35] ASTM D6648-16, Standard Test Method for Determining the Flexural Creep Stiffness of Asphalt Binder Using the Bending Beam Rheometer (BBR), ASTM International, West Conshohocken, PA, USA, 2016.

[36] ASTM D6723-12, Standard Test Method for Determining the Fracture Properties of Asphalt Binder in Direct Tension (DT), ASTM International, West Conshohocken, PA, USA, 2012.

[37] P. G. Lavin, Asphalt Pavements: A Practical Guide to Design, Production, and Maintenance for Engineers and Architects, Spon Press, New York, NY, USA, 2003.

[38] ASTM D6373-16, Standard Specification for Performance Graded Asphalt Binder, ASTM International, West Conshohocken, PA, USA, 2016. 